\title{
Fisuras labiopalatinas en el antiguo Perú
}

\author{
Cleft lip and palate in the ancient Peru
}

Emiliano Paico-Vílchez ${ }^{1}$ y Emiliano Paico-Zumaeta ${ }^{2}$

\section{Resumen}

En este artículo, los autores muestran la presencia de las fisuras labiopalatinas entre los aborígenes peruanos, tal como fue representada en la cerámica de los Mochicas y Chimúes; así mismo, las referencias de los antiguos cronistas que los aborígenes tenían esta malformación congénita. La fisura labiopalatina es una malformación que fue frecuente entre los aborígenes peruanos. Era considerada un signo de poseer poderes sobrenaturales; $\mathrm{y}$, a los portadores de esta malformación se les consideraba intermediarios entre lo divino y lo terrenal, por lo que podían desempeñarse como curanderos o sacerdotes.

Palabras clave: fisura labiopalatina, ceramios, Mochica, Chimú, cronistas, Inca.

\begin{abstract}
In this article, the authors show the presence of cleft lip-palate among Peruvian aborigines, as represented in the ceramics of the Mochicas and Chimus; likewise, the references of the ancient chroniclers that the aborigines had this congenital malformation. The cleft lip-palate is a malformation that was common among Peruvian aborigines. It was considered a sign of possessing supernatural powers; and, the carriers of this malformation were considered intermediaries between the divine and the earthly, so they could act as medicine men or priests.
\end{abstract}

Keywords: cleft li-palate, ceramics, Mochica, Chimu, chroniclers, Inca.

1. Cirujano pediátrico, profesor de la Universidad Privada Antenor Orrego. Ex jefe del servicio de cirugía pediátrica y del servicio de especialidades quirúrgicas del Hospital Belén de Trujillo, Perú.

2. Estudiante de la Facultad de Ciencias de la Comunicación de la Universidad Privada Antenor Orrego, Trujillo, Perú.

\section{Introducción}

La fisura o hendidura del labio, conocida también con el nombre del labio leporino por su similitud al labio de los lepóridos (liebre, conejo) es una malformación congénita que existió entre los aborígenes peruanos desde tiempos muy remotos. Esta malformación se caracteriza por presentar en el labio superior una solución de continuidad tipo fisura casi vertical, que puede o no dividir completamente al labio. La fisura puede ser unilateral o bilateral, parcial o total y, más raramente, medial. Puede comprometer al paladar secundario, denominándose entonces fisura labiopalatina.

La primera evidencia de la existencia de la fisura labiopalatina entre los aborígenes peruanos se encuera en la cerámica de las culturas Mochica y Chimú, y no son pocos los ceramios con esta patología que se exhiben en los museos arqueológicos. Los ceramistas han representado con un realismo y verosimilitud admirable rostros de aborígenes peruanos con fisura del labio.

También existe evidencias osteológicas, aunque en menor cantidad, de esta patología en cráneos del antiguo Perú. Por ejemplo, Altamirano y García ${ }^{1}$ han estudiado un cráneo incaicO, que se encuentra 
en el Museo Nacional de Arqueología, Antropología e Historia del Perú, con clara evidencia de una fisura labiopalatina. Los investigadores infieren que se trataba de una mujer de 30 a 35 años de edad, cuyo cráneo fue descubierto en Makatampu, en el valle bajo del Rímac, sitio arqueológico destruido por la expansión urbana y centralista de Lima en las décadas de 1940 y 1950. El doctor José Peiró ${ }^{2}$ refiere la existencia de un cráneo precolombino peruano que se encuentra en Berlín, en la colección antropológica de Rudolf Virchow, en el que se evidencia una fisura palatina completa. Se cree que este cráneo sirvió como modelo al pintor francés Paul Cézanne para pintar en 1901 su obra "Pirámide de cráneos" donde aparece reflejada la fisura palatina. Estas evidencias osteológicas -probablemente existen más- refuerzan lo registrado por los ceramistas mochicas y chimúes en sus admirables ceramios.

Información de las fisuras labiopalatinas también nos la proporcionan los cronistas españoles, la gran mayoría religiosos, que viajaron por la región andina recopilando información de la vida de los aborígenes o que tuvieron la misión de prohibir las idolatrías. Los cronistas mestizos también nos dan información de esta malformación, que al parecer fue frecuente entre los aborígenes peruanos.

El presente artículo tiene el propósito de dar a conocer, mediante fotografías de ceramios, la presencia del labio leporino entre los aborígenes peruanos; asimismo, dar a conocer la concepción que ellos tenían de esta deformante malformación

\section{Fisura del labio y del paladar}

Según la Organización Mundial de la Salud (OMS), la incidencia de las fisuras labiopalatinas es de un caso cada 500 a 700 recién nacidos vivos, siendo la segunda patología congénita más frecuente en los recién nacidos. La incidencia está directamente proporcional a la edad de las madres. En el Perú el nacimiento de niños con fisura del labio y del

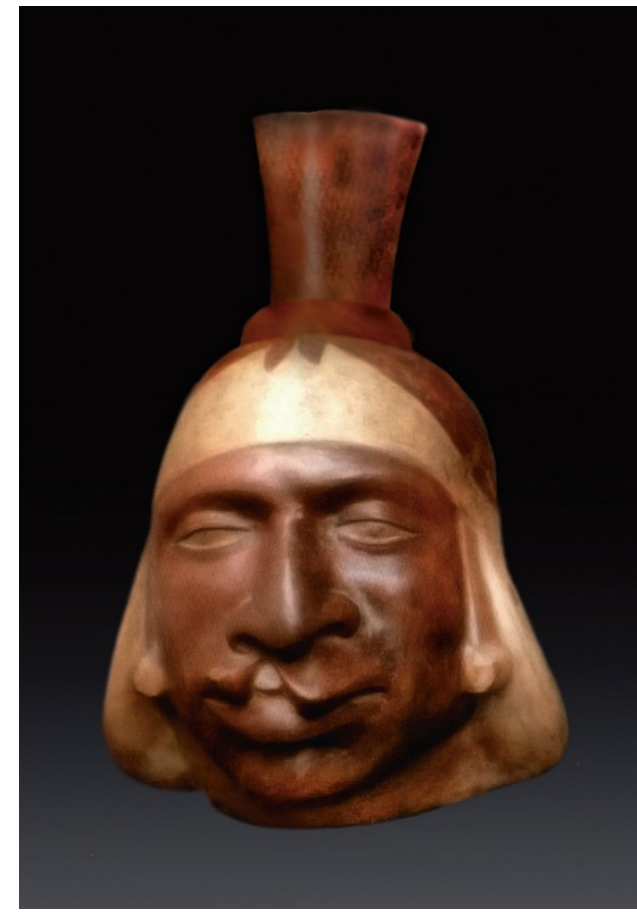

Rostro de un varón con fisura labial unilateral izquierdo completa, que compromete el labio y se extiende hacia la fosa nasal. Cerámica Mochica. Museo Nacional de Arqueología, Antropología e Historia del Perú (MNAAHP), Lima, Perú.

paladar también son frecuentes, pues la incidencia es de un caso cada 800 recién nacidos.

Existe variación de la incidencia en relación a los grupos étnicos. Las poblaciones de origen asiático tienen la mayor incidencia, los de origen caucásico de incidencia intermedia y los de origen negro la más baja. En lo que concierne al sexo, las fisuras labiopalatinas, en términos generales, son más frecuente en los varones. La fisura del labio es más frecuente en varones, mientras que la fisura palatina aislada ocurre más en mujeres.

La fisura del labio frecuentemente es unilateral (80 $\%$ de los casos), y es menos frecuente la bilateral (20\% de los casos). Las unilaterales ocurren generalmente en el lado izquierdo. La fisura del labio a menudo (70 \% de los casos) se acompaña de fisura del paladar. 


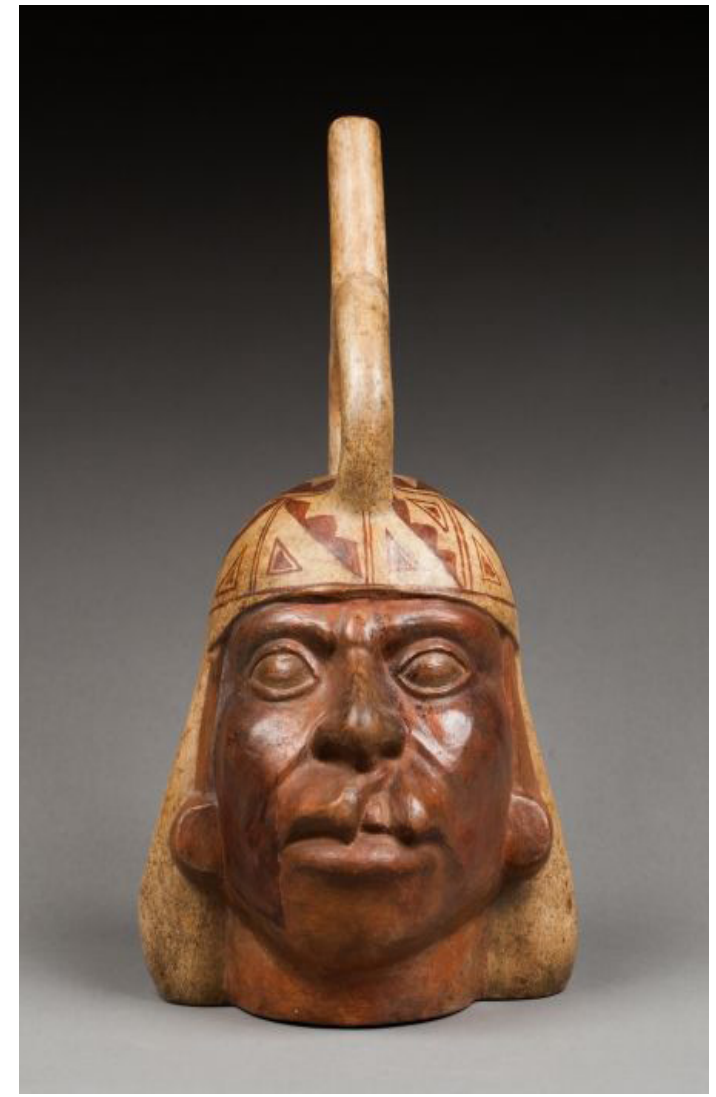

Representación de un rostro con fisura labial unilateral izquierdo completa. Cerámica Mochica. MNAAHP.

En ocasiones las fisuras del labio y del paladar se asocian a otros tipos de malformaciones, que a menudo forman parte de diversos síndromes. En algunos de los síndromes en los que se evidencia fisura del labio o fisura del paladar, las malformaciones pueden ser más grave como en el caso de ciertos síndromes cromosómicos. Mientras más profunda, extensa y grave es la fisura, mayor es la posibilidad de una malformación asociada. Las malformaciones asociadas generalmente se ubican en la cabeza y afectan a las estructuras vecinas a los labios, tales como ojos, pabellones auriculares, esqueleto maxilofacial, etc.

En relación a la etiopatogenia, no se ha determinado con precisión, y se cree que en la misma están involucrados factores hereditarios, ambientales (teratógenos) y desconocidos. Sin embargo, para la

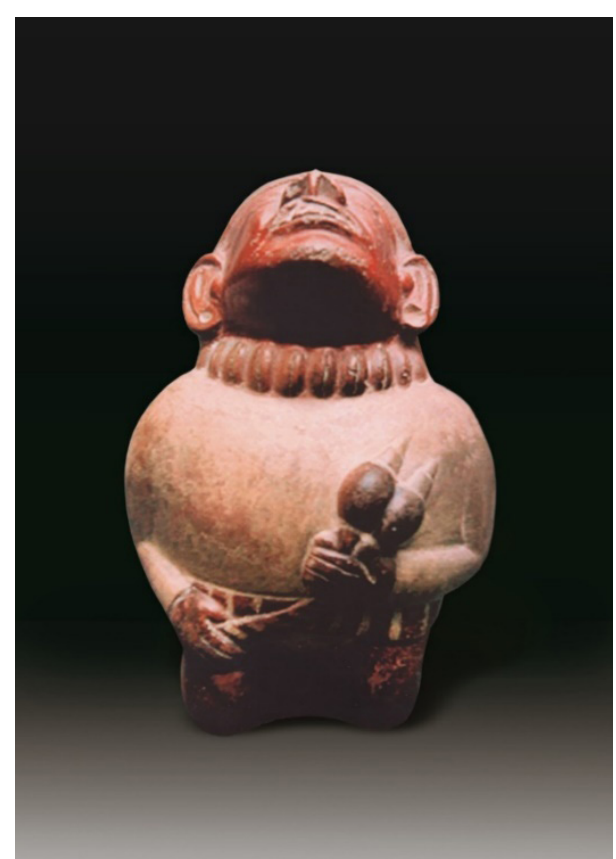

Curandero con fisura labial, arrodillado y con sonajas, en actitud de invocación. Cerámica Mochica. Museo de Arqueología y Antropología de la Universidad Nacional de Trujillo (MAAUNT), Trujillo, Perú.

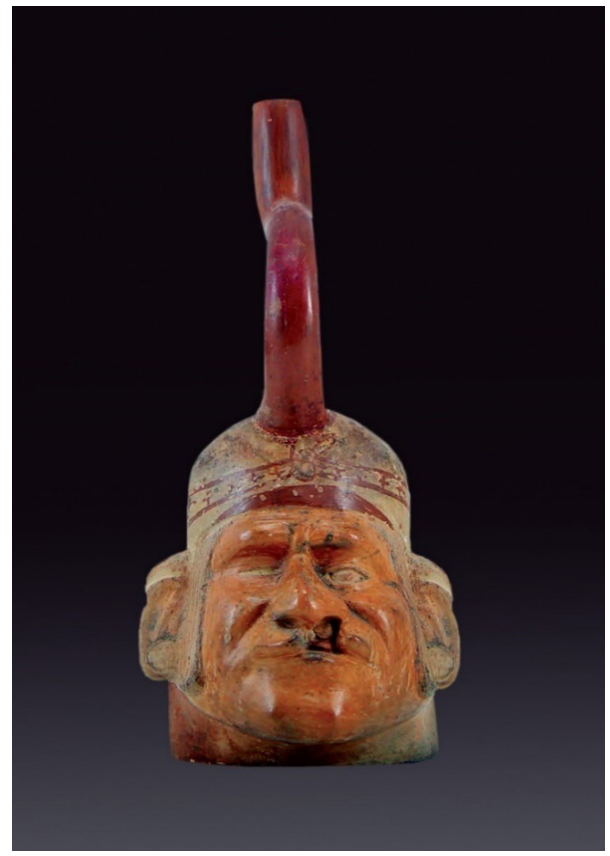

Rostro de un varón ciego del ojo derecho con fisura labiopalatina unilateral completa (compromete el labio y se extiende hacia la fosa nasal). Cerámica Mochica. MNAAHP. 
mayoría de investigadores la etiopatogenia de las fisuras labiopalatinas ocurriría frecuentemente por la interacción de factores ambientales con factores genéticos. Así, parece que el medio interactúa con la genética materna y fetal, de tal forma que la variación genética es la que modula el riesgo de defectos. ${ }^{3}$

Esta malformación anatómica produce alteraciones en la alimentación, trastornos del lenguaje y de la fonación, enfermedades del oído medio y pérdida de la audición, infecciones de las vías aéreas superiores, problemas dentales y ortodóncicos, alteraciones del crecimiento maxilofacial, alteraciones psicológicas y problemas estéticos.

Como se puede inferir, esta deformante malformación requiere, imprescindiblemente, un manejo terapéutico multidisciplinario oportuno y adecuado, lo que se consigue en forma planificada durante largo tiempo.

\section{Fisura del labio y del paladar en los aborígenes}

El pensamiento mítico que reinaba en el mundo espiritual de los aborígenes peruanos les hacía concebir que las malformaciones congénitas externas, como el labio leporino, eran atribuidas a la exposición de la gestante al rayo (illapa), que era uno de los dioses del olimpo incaico. El dios Illapa era un dios trino compuesto por el rayo, el relámpago y el rayo. Bajo esa concepción, a los recién nacidos con malformaciones congénitas, como la fisura del labio, se les consideraban seres especiales, pues se creía que la malformación era un signo de tener poderes sobrenaturales. Se les consideraba intermediarios entre lo divino y lo terrenal; por lo tanto, las personas podían ejercer, en el futuro, las funciones de sacerdote o de médico. Eran personas muy apreciadas y respetadas por el Estado y por su sociedad.

El cronista napolitano jesuita Giovanni Anello $\mathrm{Oliva}^{4}$, refiriéndose a los recién nacidos con

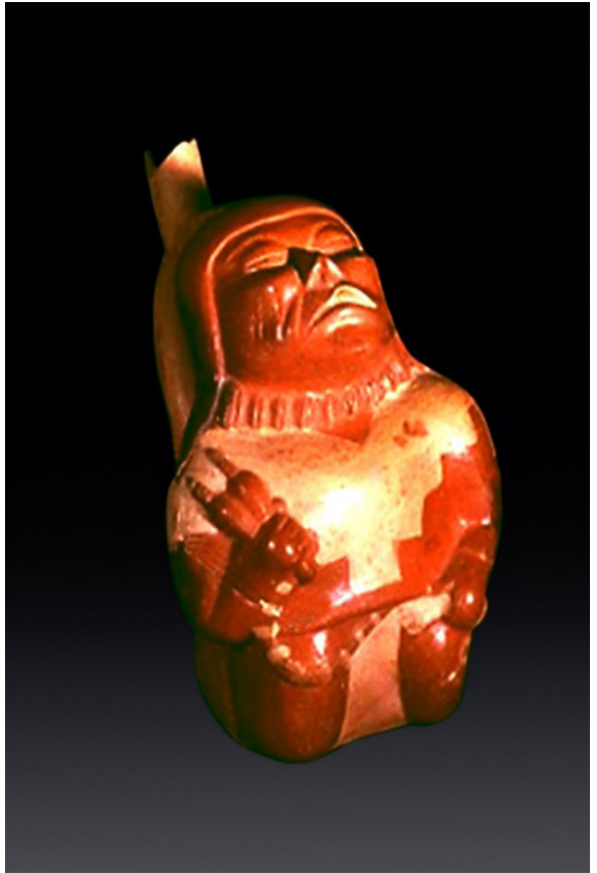

Médico con fisura labial unilateral izquierda completa, arrodillado y con sonajas en actitud de invocación. Cerámica Mochica. MNAAHP.

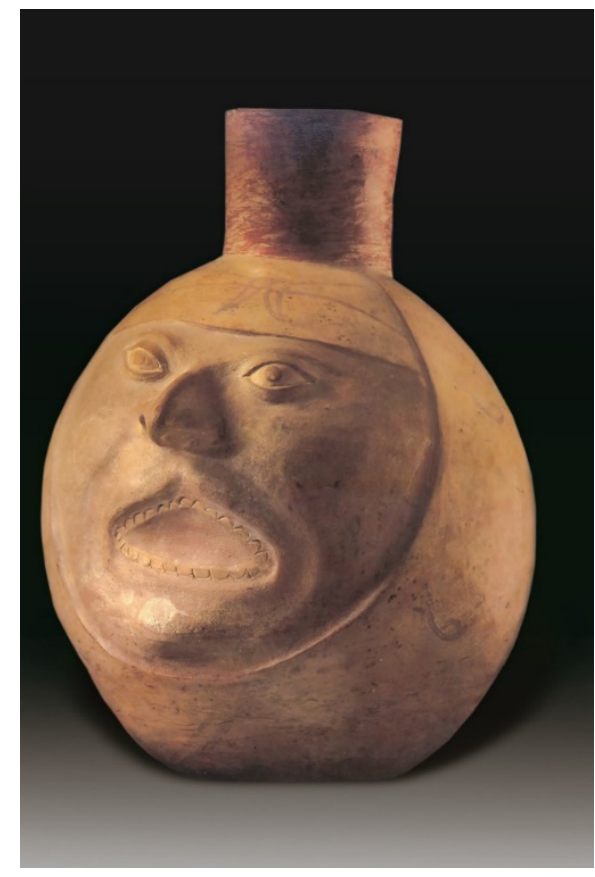

Rostro de un individuo con fisura del labio parcial unilateral. Mochica. Museo Arqueológico Rafael Larco Herrera (MARLH), Lima, Perú. 


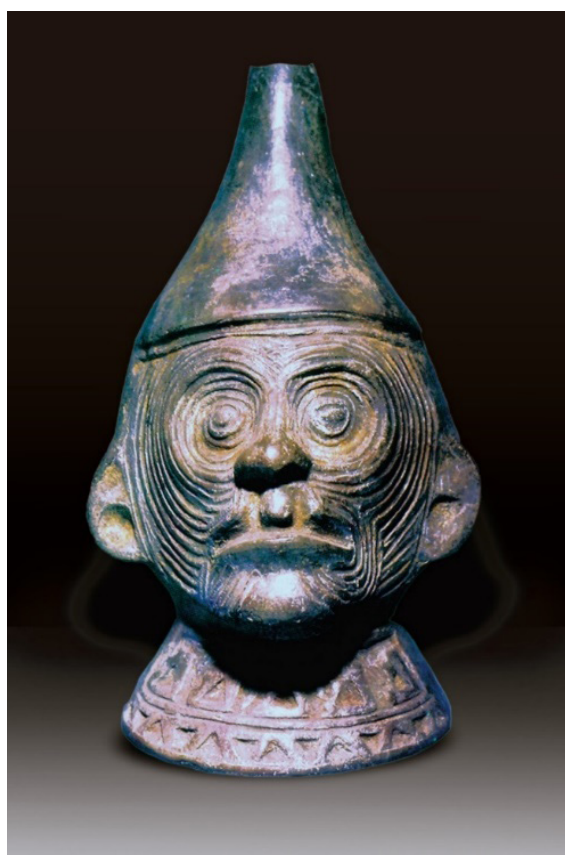

Rostro de un individuo con fisura labiopalatina bilateral completa (compromete las partes blandas del labio, parte de la fosa nasal y el paladar) y con escarificaciones. Cerámica Chimú. MARLH.

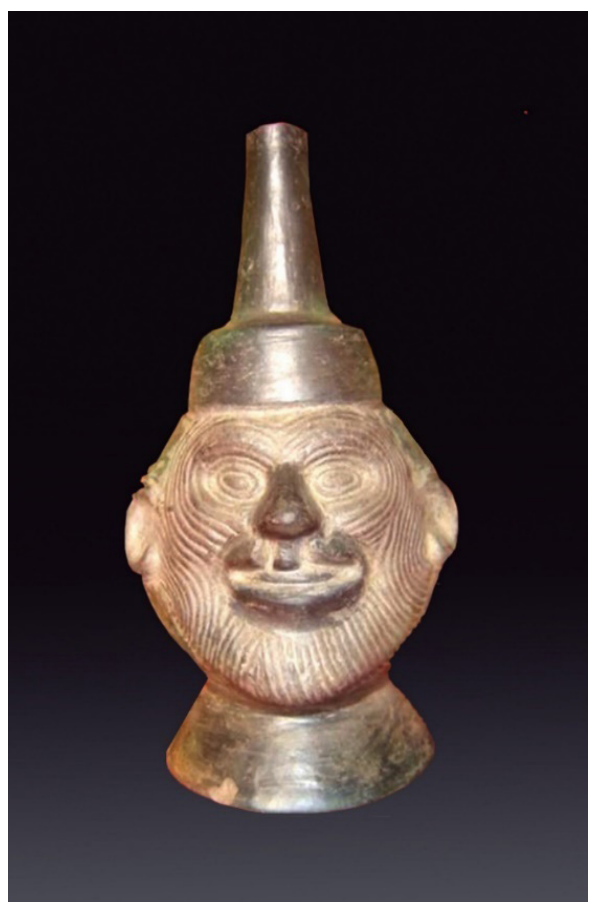

Rostro de un individuo con fisura labiopalatina bilateral completa y escarificaciones. Cerámica Chimú. Museo Arqueológico Cassinelli (MAC), Trujillo, Perú.

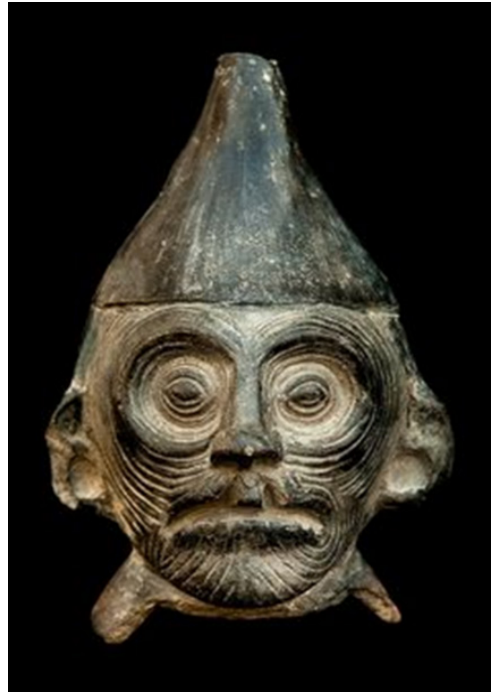

Rostro de un individuo con fisura labiopalatina bilateral completa y escarificaciones. Cerámica Chimú. MNAAHP.

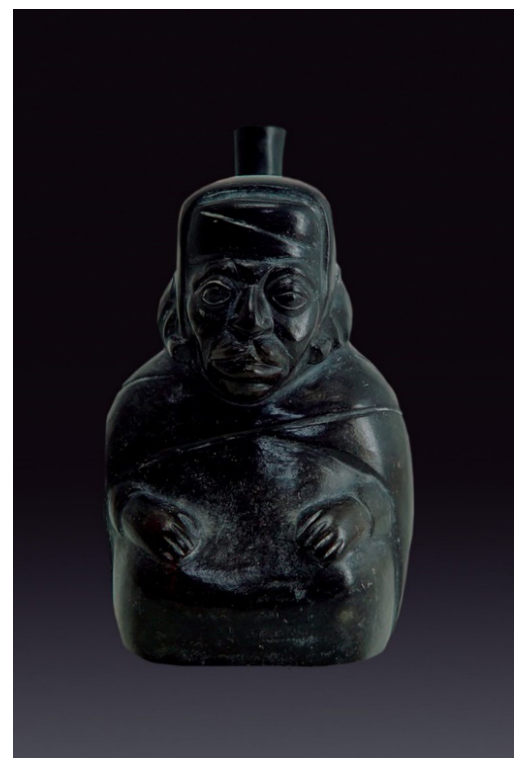

Representación de una persona con fisura labial unilateral completa. Cerámica mochica. MARLH.

malformaciones congénitas que en el futuro ejercían las funciones de médico, manifiesta que cuanto más grave era la malformación, más acertados o eficaces eran los curanderos y, por lo tanto, eran más solicitados y venerados. Este cronista en su libro 


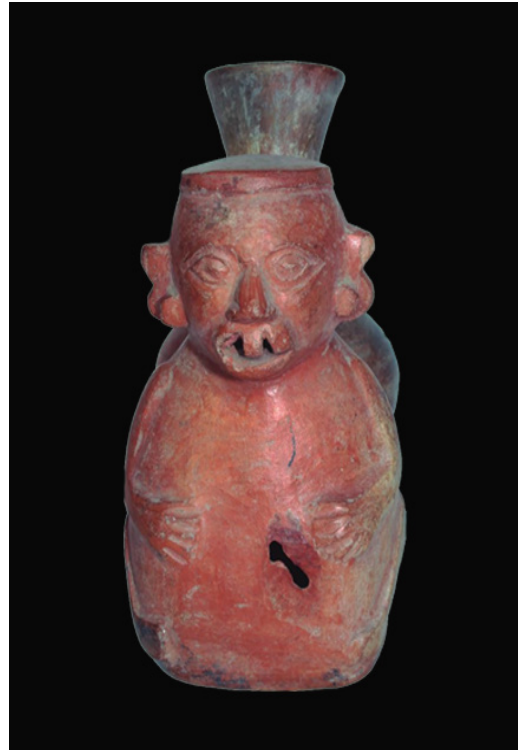

Representación de un individuo con fisura labiopalatina bilateral completa. Cerámica Chimú. MARLH.

Historia del Reino y Provincias del Perú y Vida de los Varones Insignes de la Compañia de Jesús, textualmente anota lo siguiente: “... y lo mismo tienen quando alguna criatura en su nacimiento sale señalada. Y asi entrando en edad los mas destos dan hechicero, sortilegios y adivinos. $Y$ quanto más lisiado fuere uno destos le tienen y veneran por mayor hechicero".

Si los niños con malformaciones nacían muertos (óbitos), o tras el parto morían por ser la malformación incompatible con la vida, los momificaban y los guardaban en una urna de cerámica para venerarlos como prueba viviente de la voluntad divina.

Bernabé Cobo $^{5}$, cronista español jesuita, cuando escribe sobre las condiciones o requisitos para desempeñarse de curandero, refiere que los portadores de malformaciones congénitas podían ejercer esa función. Él anota lo siguiente: " $L a$ profesión se originaba con el nacimiento (heredaban la profesión de su padremédico). Debíase también a otras causas excepcionales como tener labio

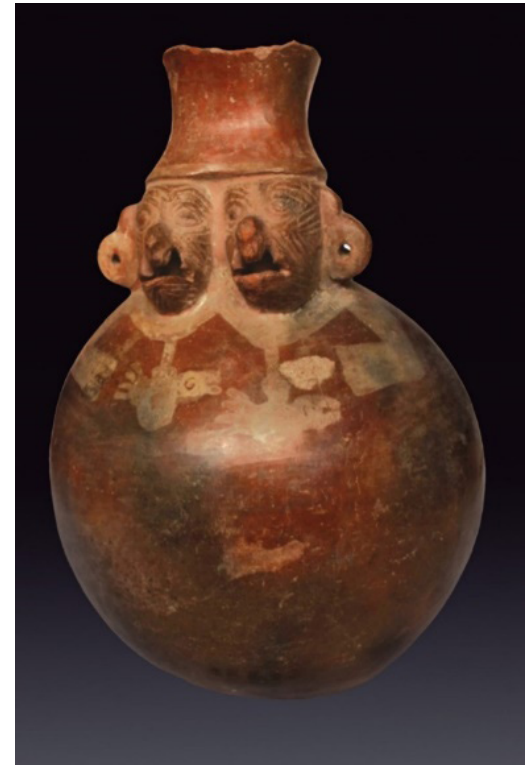

Rostros de hermanos gemelos bicéfalos con fisura labiopalatina bilateral completa. También presenta escarificaciones en la cara. Cerámica Chimú. Museo Arqueológico Nacional Brünig (MANB), Lambayeque, Perú.

leporino o nacer dos o tres del mismo vientre o tener en el cuerpo más de lo común (ej. seis dedos)”. El mismo Bernabé Cobo manifiesta que "la condición de médico implicaba ser al mismo tiempo sacerdote, mago, confesor, médico, y hechicero." Por este motivo el médico era muy venerado.

Martín de Murúa $^{6}$, cronista español jesuita, cuando se ocupa de la elección para ejercer la función de médico, incluye también a los que tienen malformaciones congénitas. Murúa anota lo siguiente: "El ejercicio de la hechicería era considerada como un oficio bajo, para gentes pobres y de poca estimación, razón por la cual los curacas que elegían a los sortilegios escogían aquellas gentes a las cuales faltaban fuerzas para el trabajo colectivo y eran, por consiguiente, personas inhábiles por su edad avanzada, por enfermedades o por defectos físicos". Obviamente, este religioso se refería a los ancianos y a los portadores de una malformación como las fisuras labiopalatinas. 
Avendaño $^{7}$, refiriéndose a la selección de magos o médicos, sostiene que "El mago generalmente es varón y que las pocas mujeres que desempeñan sus funciones son siempre viejas. El ejercicio de la magia es hereditario; pero también puede ser señalada para tal objeto por su propio curaca alguna persona que tenga defecto fisico o también que se presente voluntariamente."

Guamán Poma de Ayala ${ }^{8}$, cronista de sangre india, en su obra Nueva Crónica y Buen Gobierno refiere que los considerados hijos del rayo, es decir los illapa curi (los gemelos), los uacasinca o de nariz hendida (los que tienen fisura labiopalatina) y los yayuma uisama aguayas (los que nacen en posición podálica) podían ser magos o curanderos.

Las personas con malformaciones congénitas eran protegidas por el Estado y por la sociedad. Al respecto el cronista Guamán Poma de Ayala ${ }^{8}$, nos cuenta que en Cusco los emperadores incas reunían en un mismo barrio a ciegos, jorobados, mudos y a los que tenían la nariz hendida (labio hendido o fisura del labio), obligándoles a casarse entre los que tenían el mismo defecto o malformación con el objetivo que no se extinguiesen; además, estaban al servicio del inca. Guamán Poma de Ayala también nos refiere, como se mencionó en el párrafo anterior, los que tenían malformaciones congénitas podían desempeñarse de médicos.

En el gobierno de Topa Inca Yupanqui, si bien se sacrificaba a niños como muestra de adoración y sumisión a sus dioses y al mismo monarca inca, estaba terminantemente prohibido sacrificar a los niños portadores de malformaciones congénitas. En las informaciones que mandó levantar el virrey Toledo se reseña: "Hacían sacrificios de niños y niñas que no tuviesen defecto alguno, que los incas lo mandaban a matar y que a cada provincia enviaban a pedir dichos niños para el sacrificio; que estos eran para que tuviesen salud, buenos maizales y buen suceso en todo. Los sacrificios de niños se realizaban a la salida del sol y al medio día."
Francisco de Ávila ${ }^{10}$ ), cronista español, refiere que uno de los principales dioses de Huarochirí y Yauyos, llamado Namsapa, hijo de Illapa y Pariacaca, poseía tres enfermedades asociadas: fisura del labio o qqopya, lehismaniasis o uta y bocio o coto. Era un dios muy poderoso, conducía y protegía los canales de irrigación que transportaban el agua, elemento importante para cultivar las tierras del sol y del Estado. Namsapa era un dios muy venerado por los agricultores.

Altamirano ${ }^{1}$ )sostienequelosindígenas deHuarochirí creían que las fisuras labiopalatinas, como otras malformaciones congénitas "era una marca directa de los dioses de las montañas conduciéndose a un destino especial de elevado status sagrado; $y$ como el dios Illapa estaba simbolizado por las tres patologías del rostro indicadas, muchos hombres y mujeres de las comunidades de Huarochiri pasaron a mutilarse sus rostros y labios superiores (a veces con escarificaciones) en honra por la fe que tenian por aquella divinidad".

Por ser considerados intermediarios entre lo divino y lo terrenal, pertenecían a una élite privilegiada con estrecha vinculación con el poder político. Eran personas que portaban preciosos atuendos especialmente los que ejercían de sacerdote o curanderos como se observan en los ceramios que se presentan en este artículo; y que según Pedro Weiss $^{10}$ son retratos perfectos de las personas con malformaciones como la fisura labial.

Finalmente, se debe subrayar que algo que llama la atención en los estudios de los ceramios que representan rostros con fisuras labiopalatinas, es lo siguiente: primero, todos corresponden al sexo masculino, lo que estaría de acuerdo con la epidemiología de esta patología, la que señala que el labio leporino es más frecuente en los varones, a no ser que este hecho se deba a que los aborígenes peruanos les daban más valoración a los hombres que a las mujeres, lo que constituiría un verdadero machismo; y, segundo, que todos los ceramios 
que representan personas con fisura labiopalatina unilateral, la lesión se encuentra en el lado izquierdo, lo que estaría acorde con la epidemiología.

\section{Referencias bibliográfica}

1. Altamirano Enciso AJ y García Zapata MA. Un caso de fisura labiopalatina o "boca de- lobo" en Makatampu, valle del Rímac, Perú, siglos XV, XVI. Revista do Museu de Arqueologia e Etnologia, Sao Paulo, 20: 361-380, 2010

2. Peiró Ibáñez José Luis. Reparación intrauterina del labio leporino en el feto ovino. Tesis doctoral. Universidad Autónoma de Barcelona. 2014.

3. Giugliano Carlos. Patología de Cabeza y cuello. En Rostión Carmen Gloria: Cirugía Pediatrica. $2^{\text {a }}$ Edición. Santiago de Chile: Edit. Mediterráneo, 2013.

4. Oliva Anello, padre Giovanni. Historia del Reino y Provincias del Perú y Vida de los Varones Insignes de la Compañía de Jesús (1631). Lima: Fondo Editorial de la Pontificia Universidad Católica del Perú, 1998.

5. Cobo, padre Bernabé. Historia del Nuevo Mundo (1653). Madrid, Atlas, 1956.

6. Murúa, Fray Martín. Historia General del Perú (1615). Madrid: Dastin, S.L., 2001.
7. Avendaño, Fernando de. Relación sobre idolatría. (1617). En: La Imprenta en Lima. Vol. I, Por J. T. Medina. Santiago: José Toribio Medina, 1904: 380-383.

8. Guamán Poma de Ayala, Felipe. Nueva Crónica y Buen Gobierno (1615). Tomo I, Lima: Fondo de Cultura Económica, 2005.

9. Hernández Príncipe Rodrigo. Mitología Andina (1622). Revista Inca, I (1): 25-78, Lima: Museo de Antropología de la Universidad Mayor de San Marcos, 1923

10. Ávila, Francisco de. Dioses y hombres de Huarochirí (1598). Fondo Editorial de la Universidad Antonio Ruiz de Montoya, Lima 2007.

11. Weiss Pedro. Paleopatología americana. Boletín de Lima.1984;6(33):17-52.

\section{Correspondencia:}

Emiliano Paico-Vílchez

epaicov@gmail.com

Fecha de recepción: 01-01-2021.

Fecha de aceptación: 15-06-2021.

Conflicto de interés: ninguno, según los autores.

Financiamiento: por los autores. 